(iii) ERS

Thank you for viewing this presentation. We would like to remind you that this material is the property of the author. It is provided to you by the ERS for your personal use only, as submitted by the author.

(c) 2016 by the author 


\section{(1) ERS}

\section{0-20 system EEG Placement}

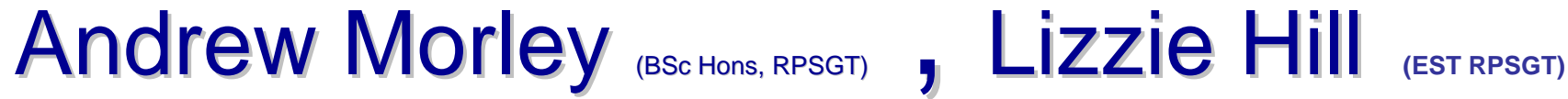

Chief Respiratory (Sleep) Physiologist, Royal Hospital for Children, Glasgow
Specialist Respiratory Clinical Physiologist, Royal Hospital for Sick Children, Edinburgh

\section{\& Prof. Dr Athanasios G. Kaditis}




\section{Conflict of interest disclosure}

\ I have no, real or perceived, direct or indirect conflicts of interest that relate to this presentation.

I I have the following, real or perceived direct or indirect conflicts of interest that relate to this presentation:

\begin{tabular}{|l|l|l} 
Afifliation / financial interest & Nature of confilict / commercial company name
\end{tabular}

Tobacco-industry and tobacco corporate affiliate

related conflict of interest

Grants/research support (to myself, my institution or

department):

Honoraria or consultation fees:

Participation in a company sponsored bureau:

Stock shareholder:

Spouse/partner:

Other support or other potential conflict of interest:

This event is accredited for CME credits by EBAP and speakers are required to disclose their potential conflict of interest going back 3 years prior to this presentation. The intent of this disclosure is not to prevent a speaker with a conflict of interest (any significant financial relationship a speaker has with manufacturers or providers of any

commercial products or services relevant to the talk) from making a presentation, but rather to provide listeners with information on which they can make their own judgment. It remains for audience members to determine whether the speaker's interests or relationships may influence the presentation.

Drug or device advertisement is strictly forbidden. 


\section{OH ERS}

\section{0-20 EEG Placement}

\section{AIMS}

- Demonstrate the International 10-20 EEG system

- Understand steps required to set-up a10-20 EEG montage for a Polysomnography sleep study.

- Give each delegate a practical experience setting up a Sleep EEG montage using the 10-20 EEG system. 


\section{OH ERS}

\section{0-20 EEG Placement}

\section{Workshop Plan}

- This session is going to be a mainly practical session.

- Brief presentation : 10-20 basics

- Split into pairs and have a go.

- Slides from the session are available as part of the workshop materials - via website

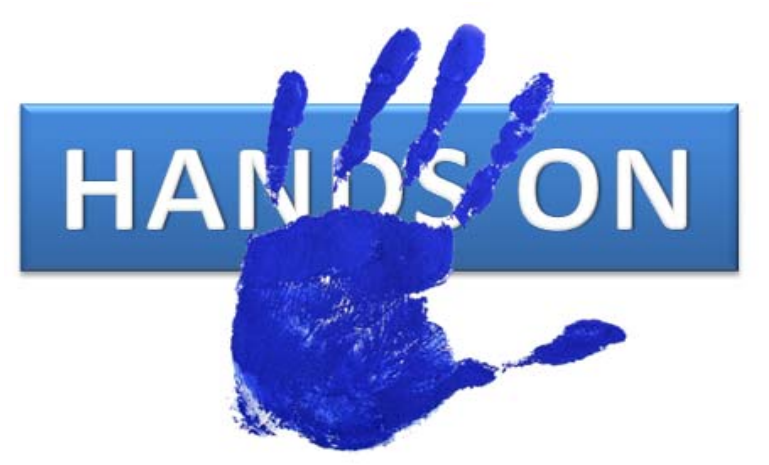




\section{OB ERS}

\section{0-20 EEG Placement}

Focus

- Head measuring

- Location of EEG, EOG, EMG

- Skin preparation / application (incl. differing techniques)

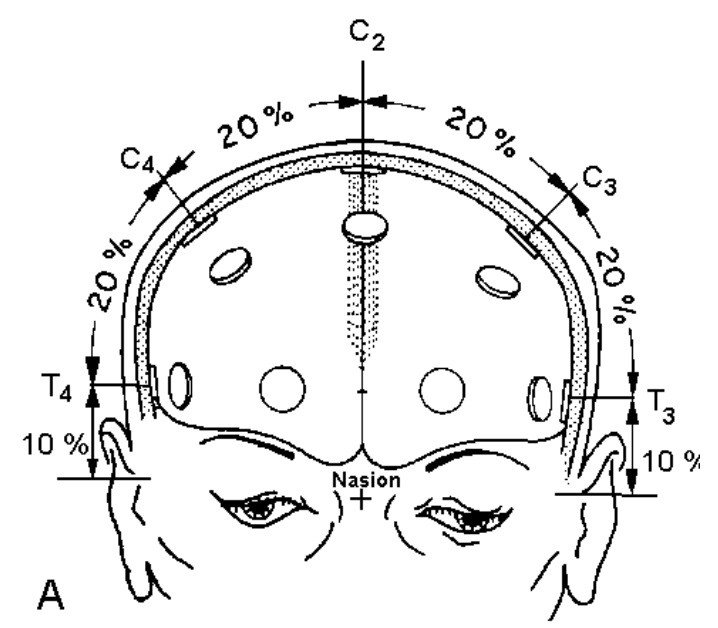




\section{OH ERS}

\section{0-20 EEG Placement}

\section{What is the $10-20$ system?}

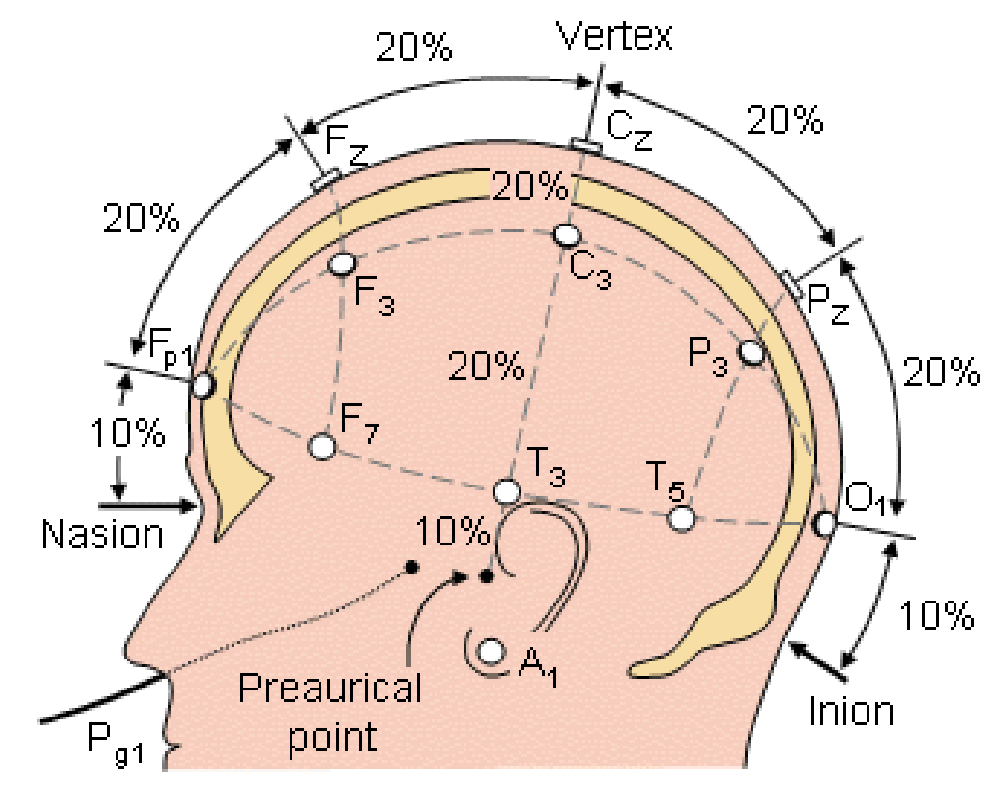




\section{O ERS}

\section{0-20 EEG Placement}

\section{What is the $10-20$ system?}

- An internationally recognised method that allows EEG electrode placement to be standardised.

- Ensures inter-electrode spacing is equal

- Electrode placements proportional to skull size \& shape

- Covers all brain regions

$$
\begin{array}{ll}
\mathrm{F}=\text { Frontal } & \mathrm{T}=\text { Temporal } \\
\mathrm{P}=\text { Parietal } & \mathrm{O}=\text { Occipital }
\end{array}
$$

- Numbering system

$$
\text { Odd }=\text { left side }, \quad \text { Even }=\text { right side }, \quad Z=\text { midline }
$$

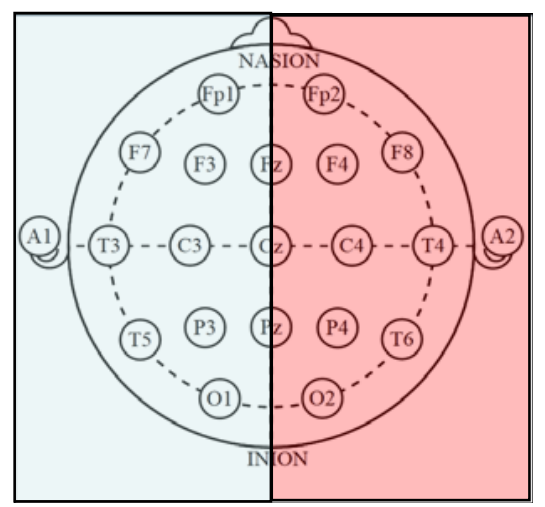




\section{(1) ERS}

\section{0-20 EEG Placement}

\section{Routine EEG Montage}

- 16 Channel (+ references e.g. cz, Ground)

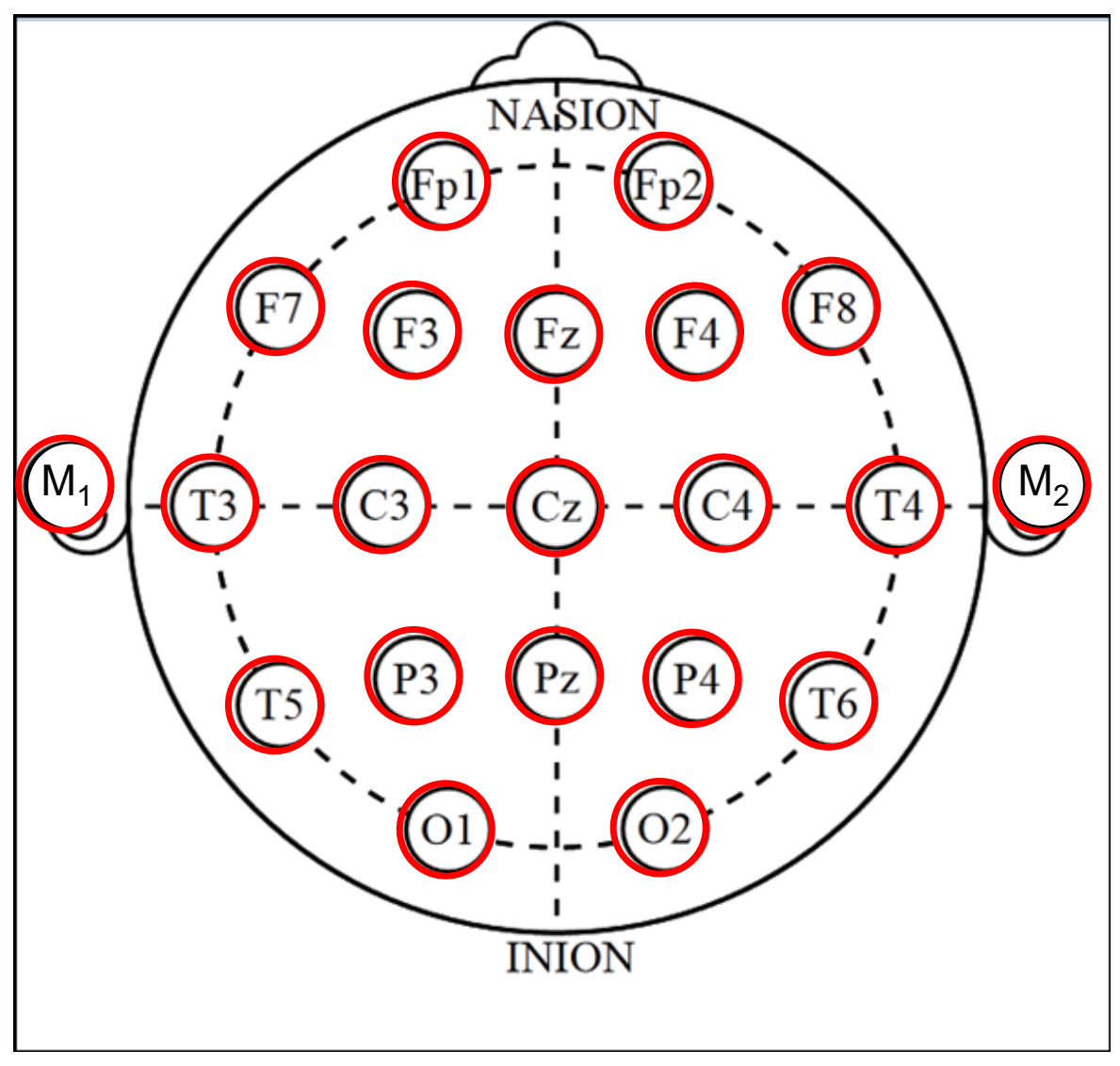

european respiratory society every breath counts 


\section{(1) ERS}

\section{0-20 EEG Placement}

American Academy of Sleep Medicine

- Utilises $10-20$ for polysomnography studies
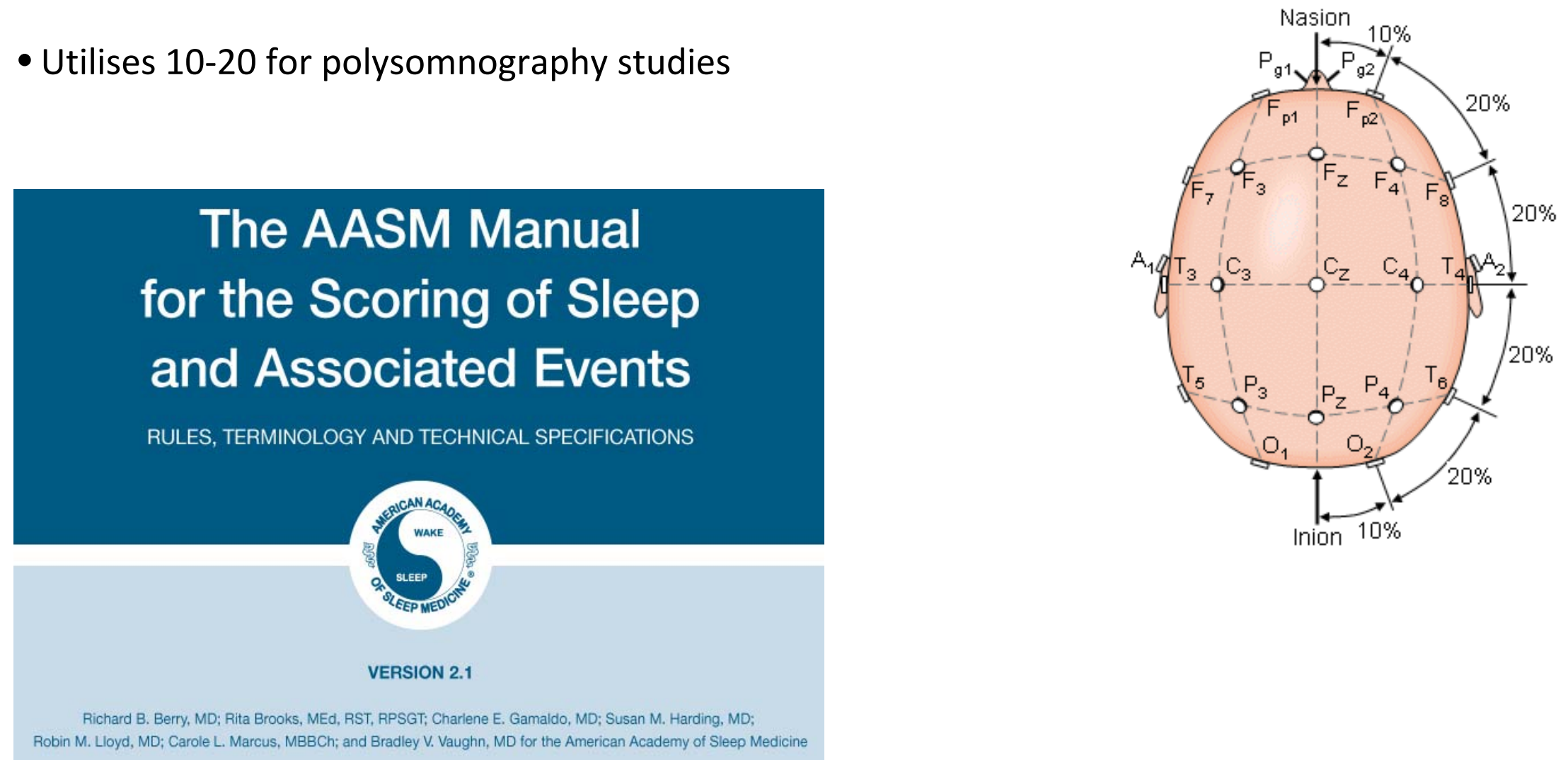


\section{O ERS}

\section{0-20 EEG Placement}

\section{Sleep Montage}

Sleep PSG montage

(8 Channels + References \& ground)

Recommended

- F3-M2

- C3-M2

- O1-M2

(There are other acceptable derivations.)

"A minimum of 3 EEG derivations are required in order to sample activity from the frontal central and occipital regions"

The AASM Manual for the Scoring of Sleep and Associated Events. Version 20

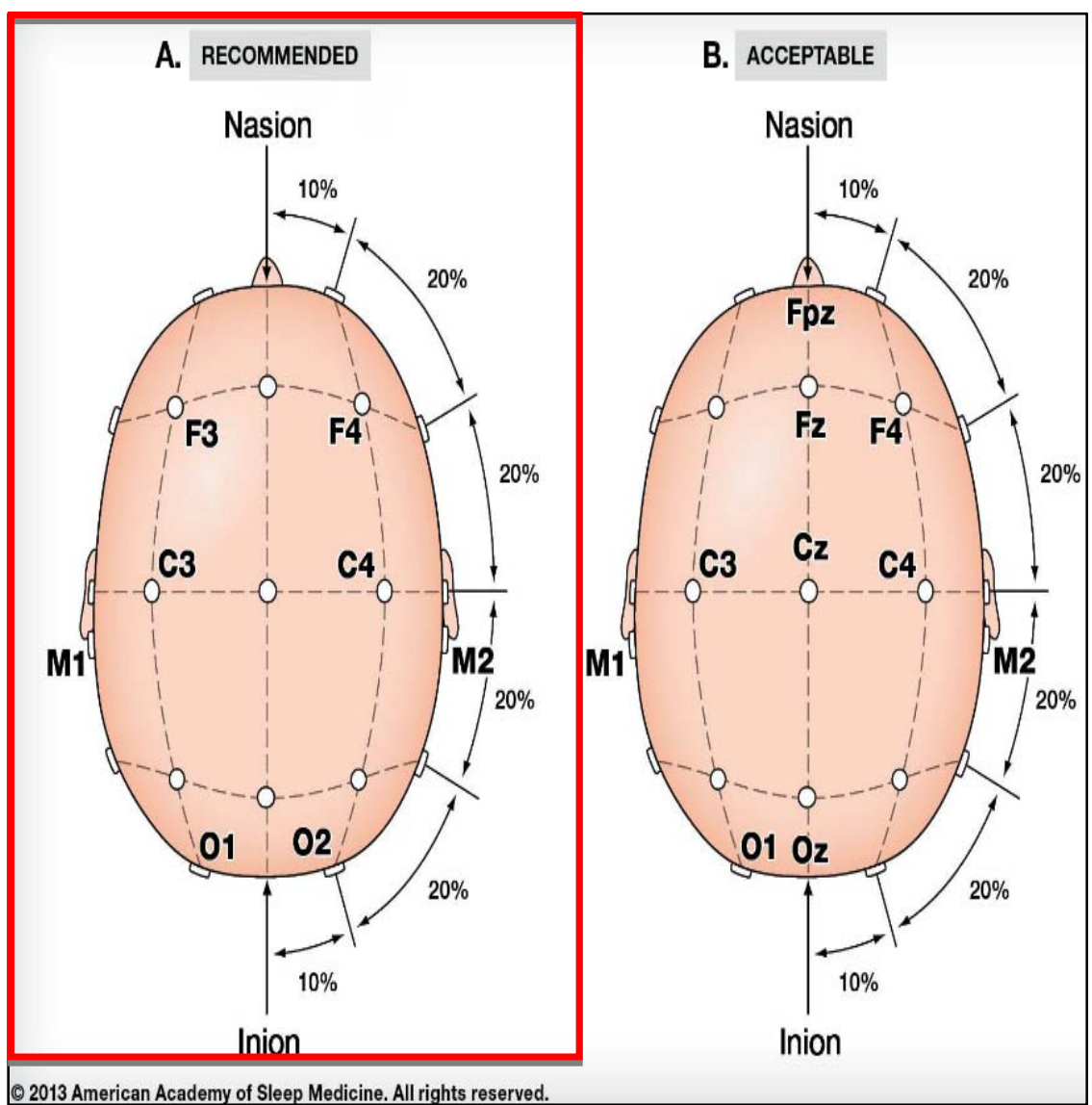

european respiratory society every breath counts 


\section{(1) ERS}

\section{0-20 EEG Placement}

Why a minimum of 3 EEG derivations?

F4-M1 - best for slow waves

0.5-2.0hz

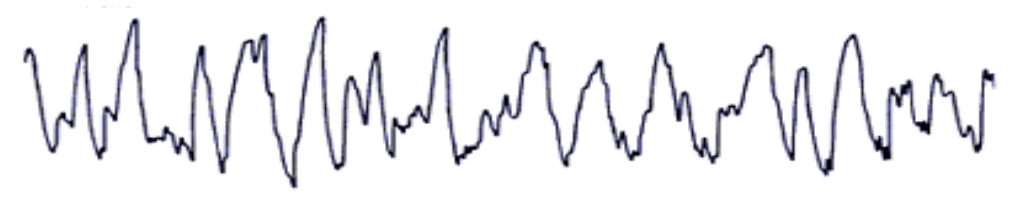

C4-M1 - best for spindles

11-16hz (most common 12-14hz)

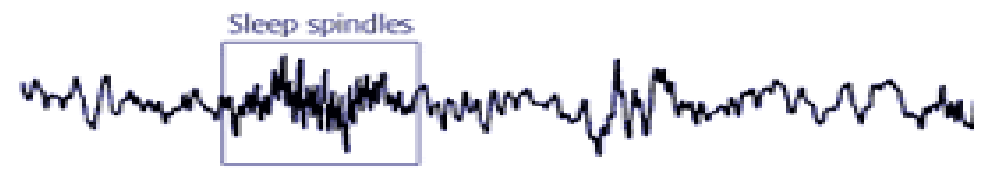

O2-M1 - best for alpha rhythm

(8-13hz)

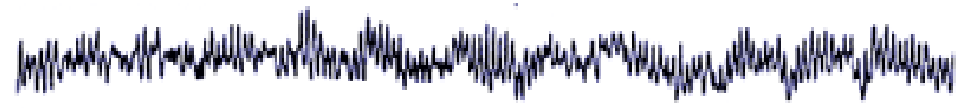




\section{(1) ERS}

\section{0-20 EEG Placement}

Preparation
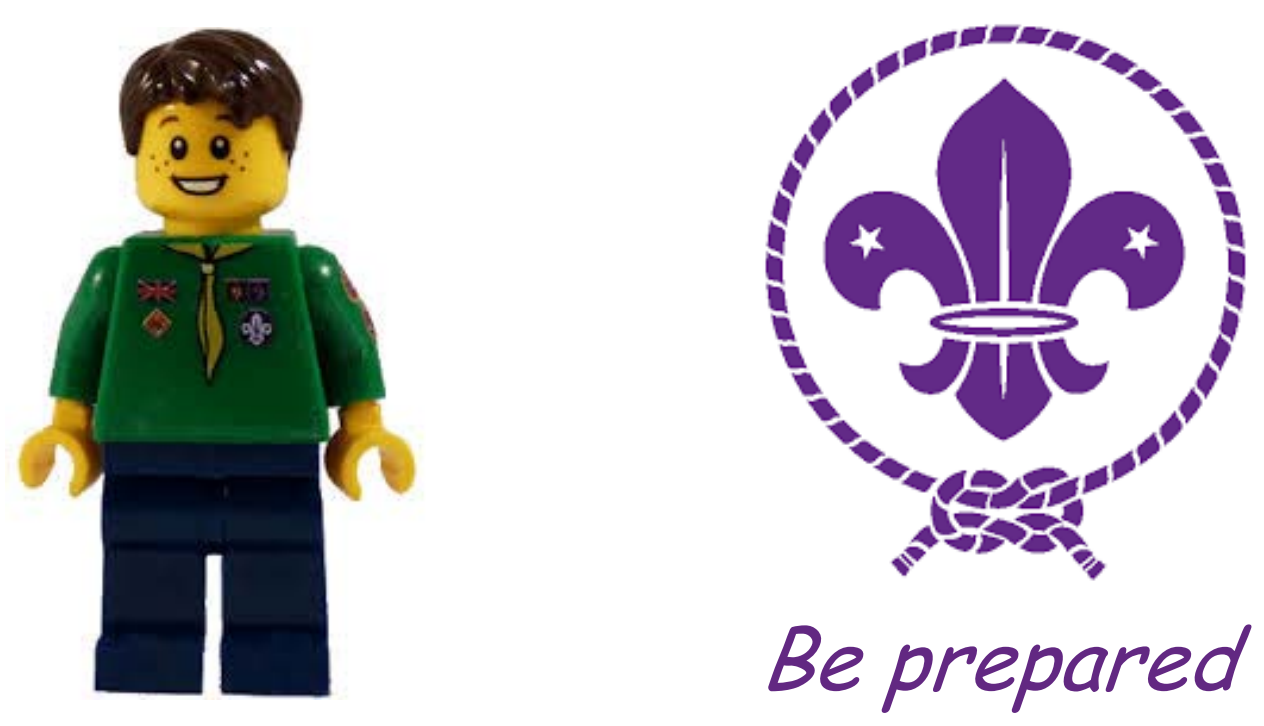


\section{(1) ERS}

\section{0-20 EEG Placement}

\section{Preparation}

You will need:

- Measuring tape

- Wax pencil

- Measurement 'cheat sheet'

- Alcohol wipes

- Scarify skin - Stick / blunt needle

- Abrasive paste

- Conductive paste/gel

- Collodion glue

- Hypafix

- Razor?
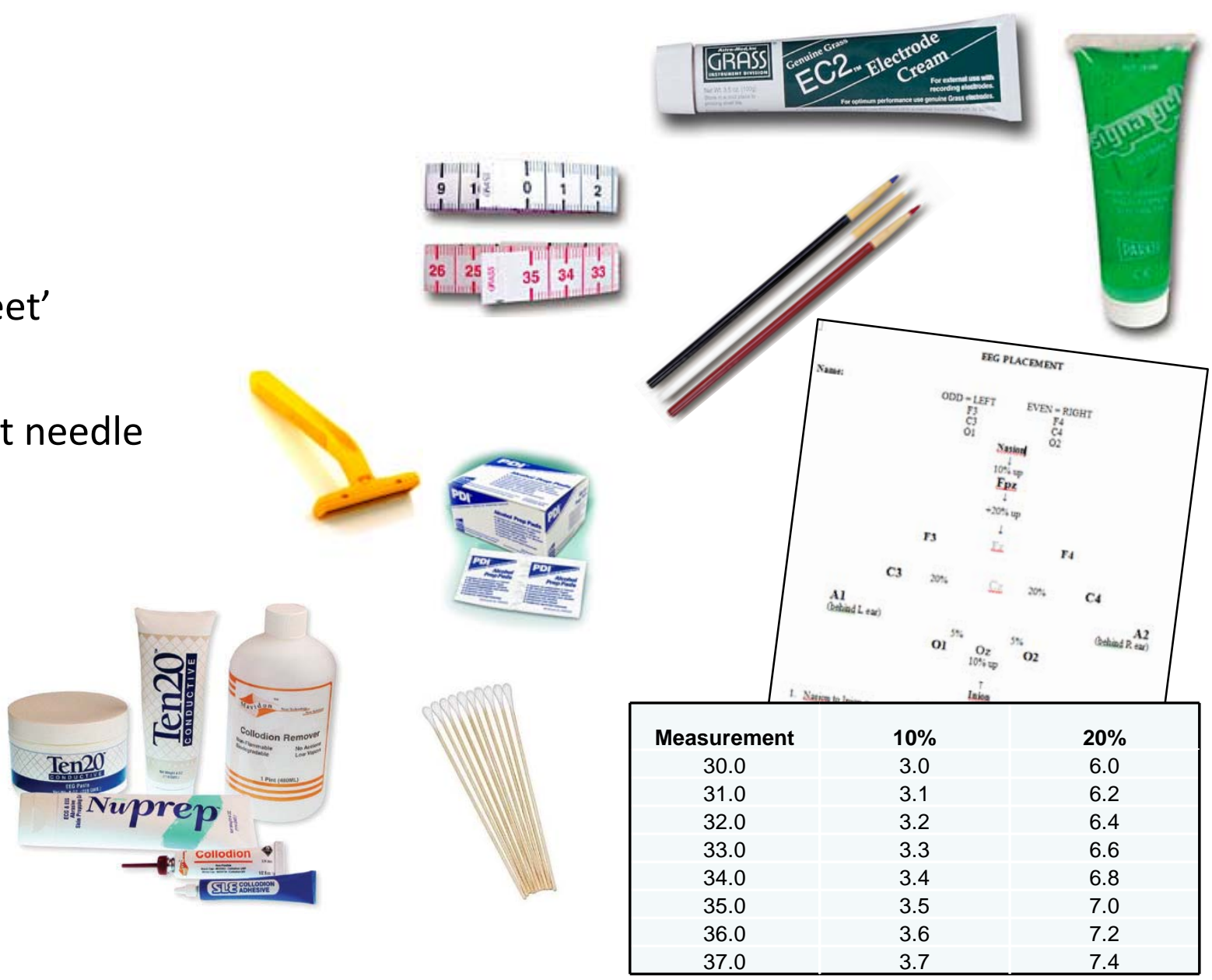


\section{OB ERS}

\section{0-20 EEG Placement}

\section{Skin Preparation}

\section{How ?}

- Isopropyl alcohol wipes to clean (removes grease)

- Abrasive paste $\&$ cotton tip to reduce skin impedance (removes dead skin cells)

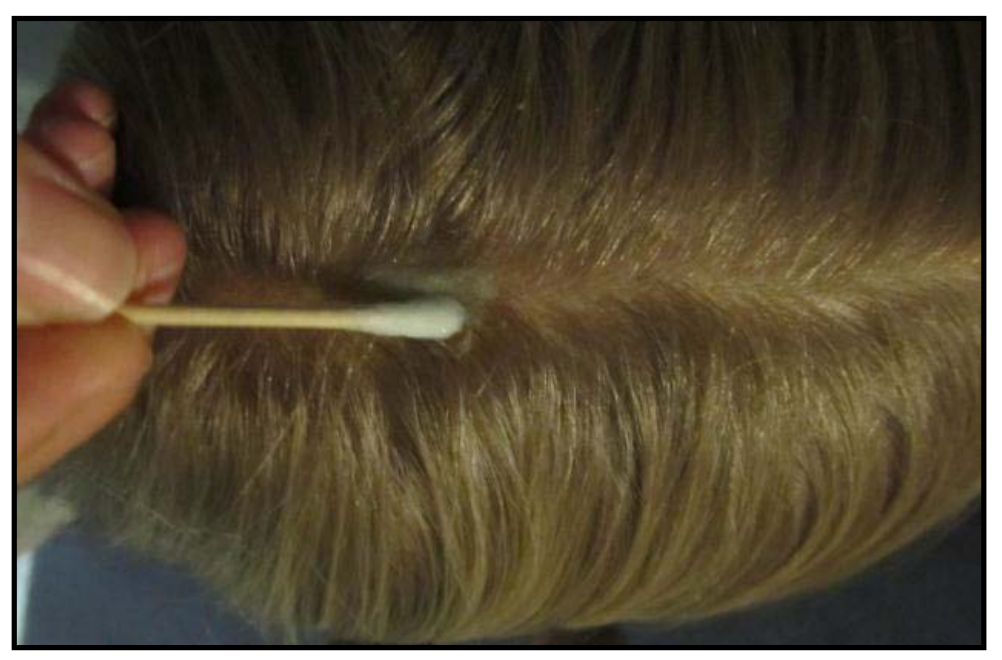




\section{(ii ERS}

\section{0-20 EEG Placement}

Why is it important

Need to have good electrical contact Impedance $<5 \mathrm{kOhms}$

Consequences of poor placement

- ECG artifact

- Movement artifact

- High impedance

- Electrode popping

- Movement artifact

- Sweat sway

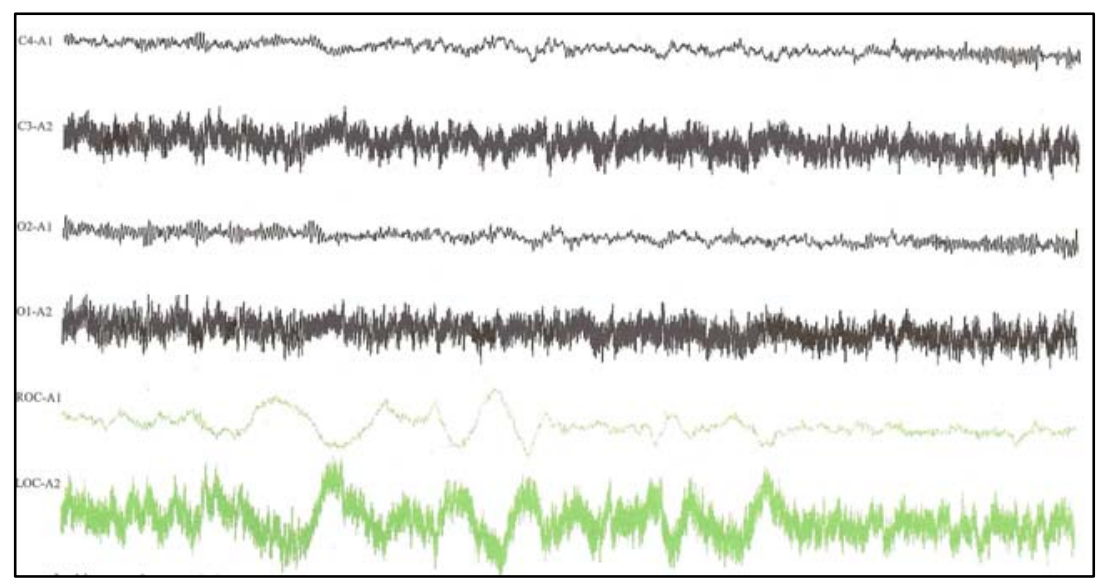

High impedance 


\section{(ii ERS}

\section{0-20 EEG Placement}

Why bother?

"Garbage In, Garbage Out"

Computers will unquestioningly process the most nonsensical of input data (garbage in) and produce nonsensical output (garbage out).

MODEL CALCULATIONS

"Garbage In-garbage Out" Paradigm
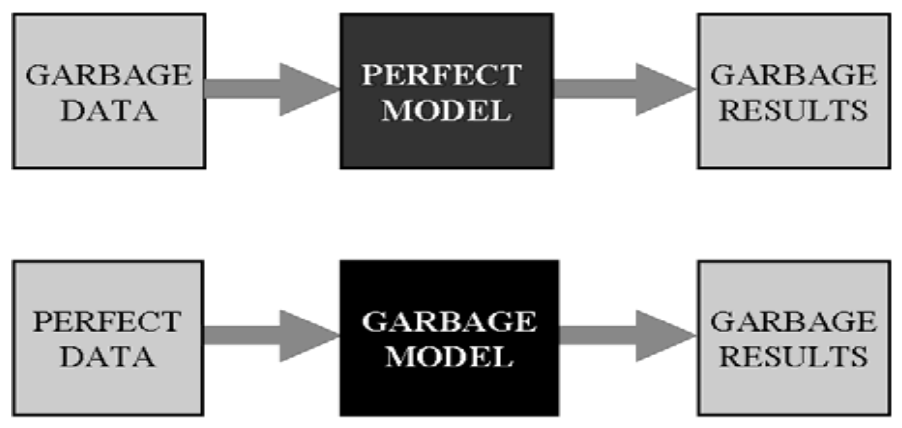

Sleep study signal pathway

Patient $\longrightarrow$ Sensor $\longrightarrow$ Headbox $\longrightarrow$ Amplifier $\longrightarrow$ Computer




\section{OH ERS}

\section{0-20 EEG Placement}

What is the $10-20$ system?

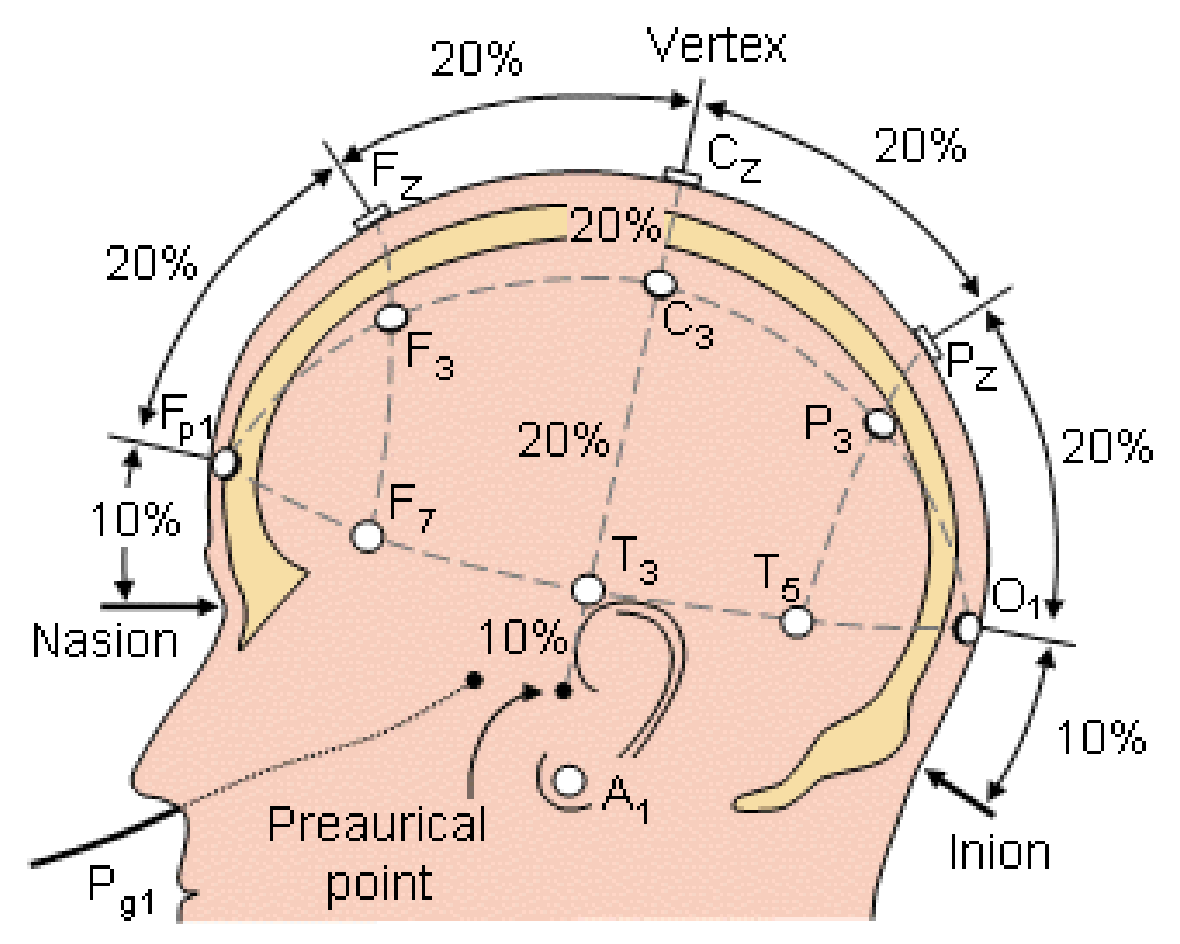




\section{Oi ERS}

\section{0-20 EEG Placement}

Four Skull Landmarks

- Nasion

- Inion

- Left Pre-auricular point

- Right Pre-auricular point
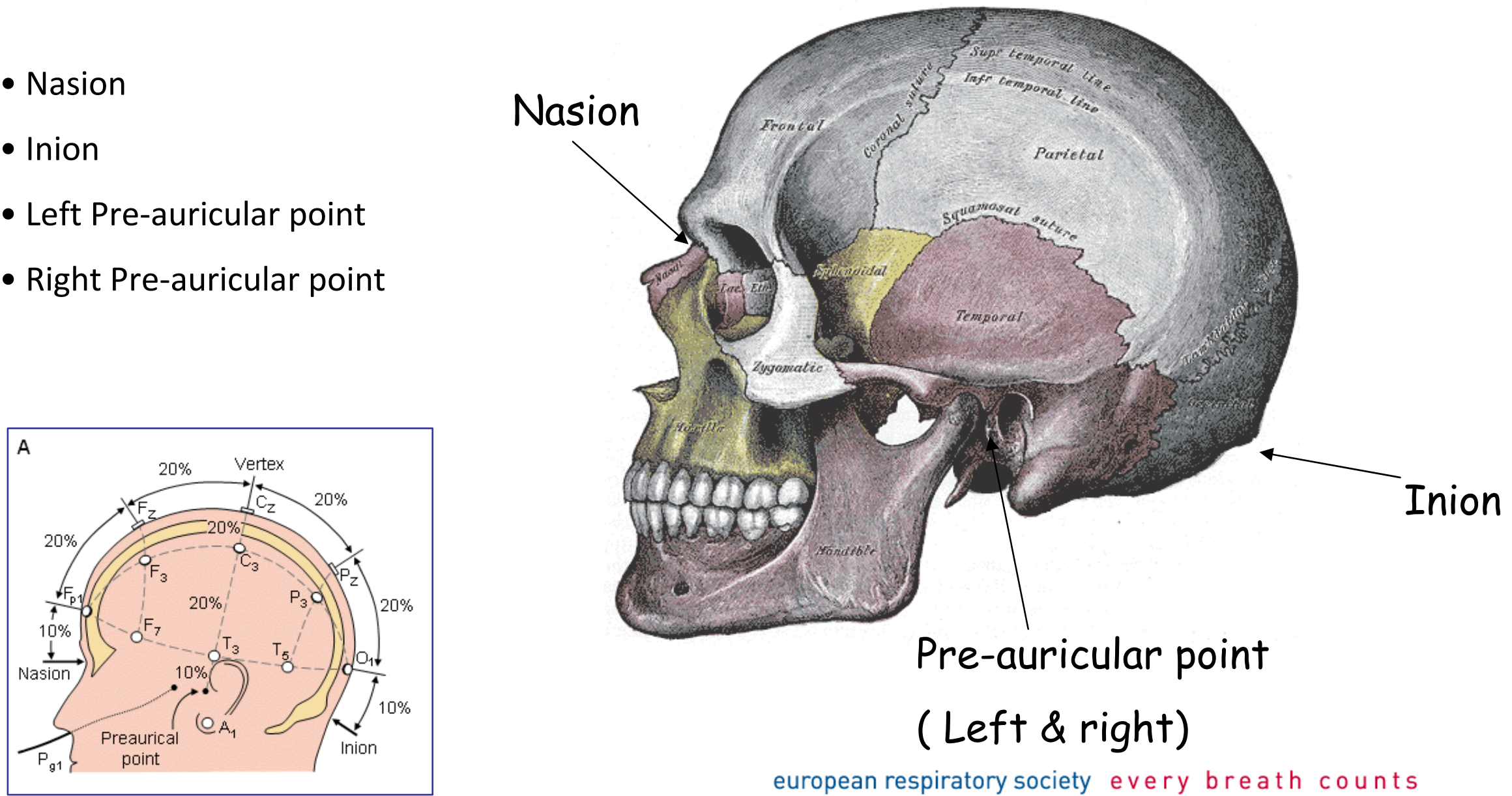


\section{(1) ERS}

\section{0-20 EEG Placement}

\section{Measurement of $C_{z}$}

- Measure the distance from pre-auricular point to preauricular point

- Mark the midpoint (50\%) with a vertical line

- This cross represents $\mathrm{Cz}$ which has been correctly aligned in the horizontal \& vertical planes

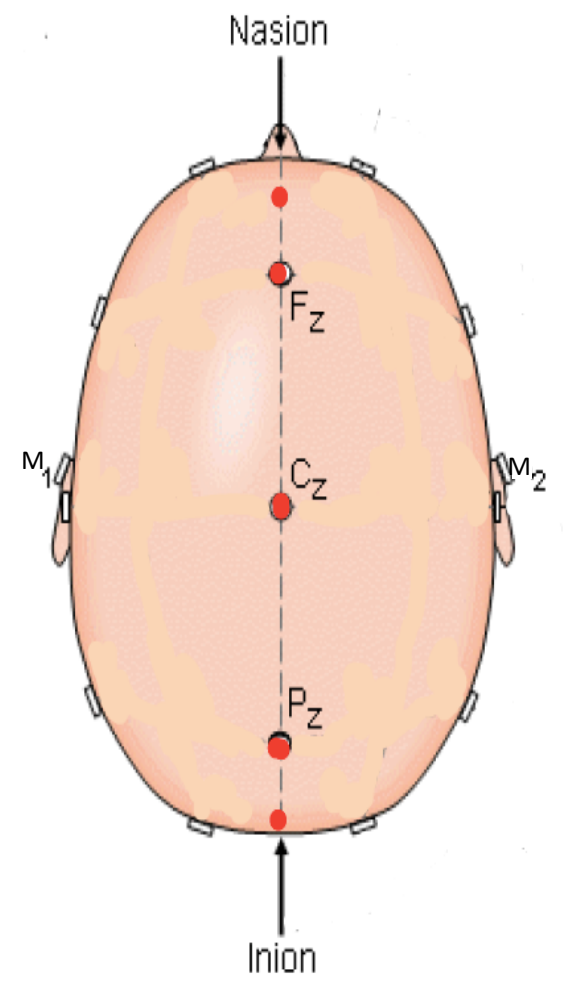




\section{OB ERS}

\section{0-20 EEG Placement}

\section{Measurements - T3, C3, Cz, C4, T4}

- Reapply the tape transversally between the pre-auricular points

- The midpoint (50\%) should cross with previous point marking for $\mathrm{Cz}$, confirming its location.

- Mark 10\%, 20\%, 20\%, 20\%, 20\%, 10\% = T3,C3, Cz, C4, T4

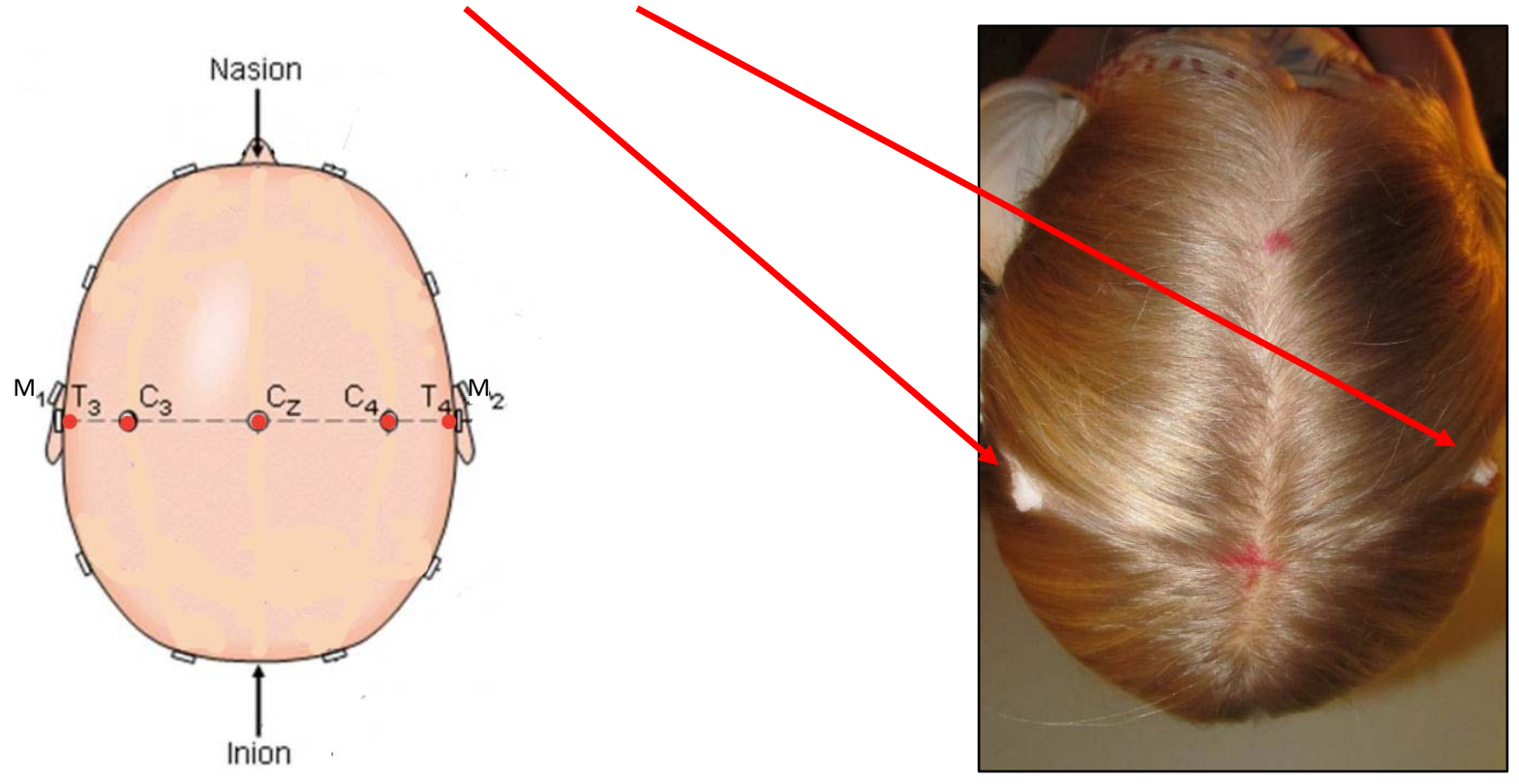




\section{(19) ERS}

\section{0-20 EEG Placement}

\section{Measurements - Fpz, Fz, Cz, Pz, Oz}

- Reapply the tape along the midline from nasion to inion

- Mark 10\%, 20\%, 20\%, 20\%, 20\%, 10\% = Fpz, Fz, Cz, Pz, Oz

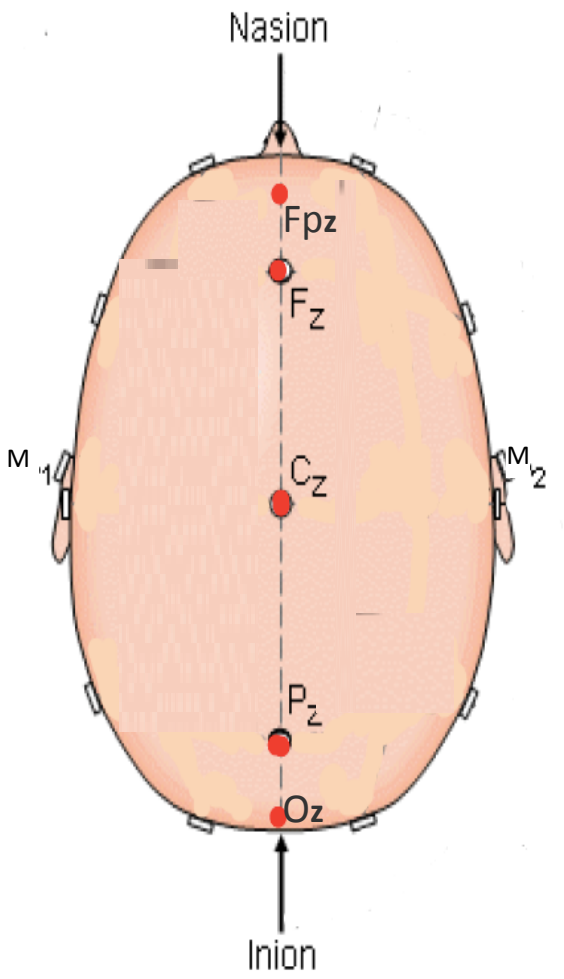




\section{OB ERS}

\section{0-20 EEG Placement}

Measurements - Fp1, F7, T3, T5, O1, Oz

- Measure the distance between Fpz \& Oz by applying the tape around the head via T3.

- Mark at 10\%, 20\%, 20\%, 20\%, 20\%, 10\% = Fp1, F7, T3, T5, O1, Oz
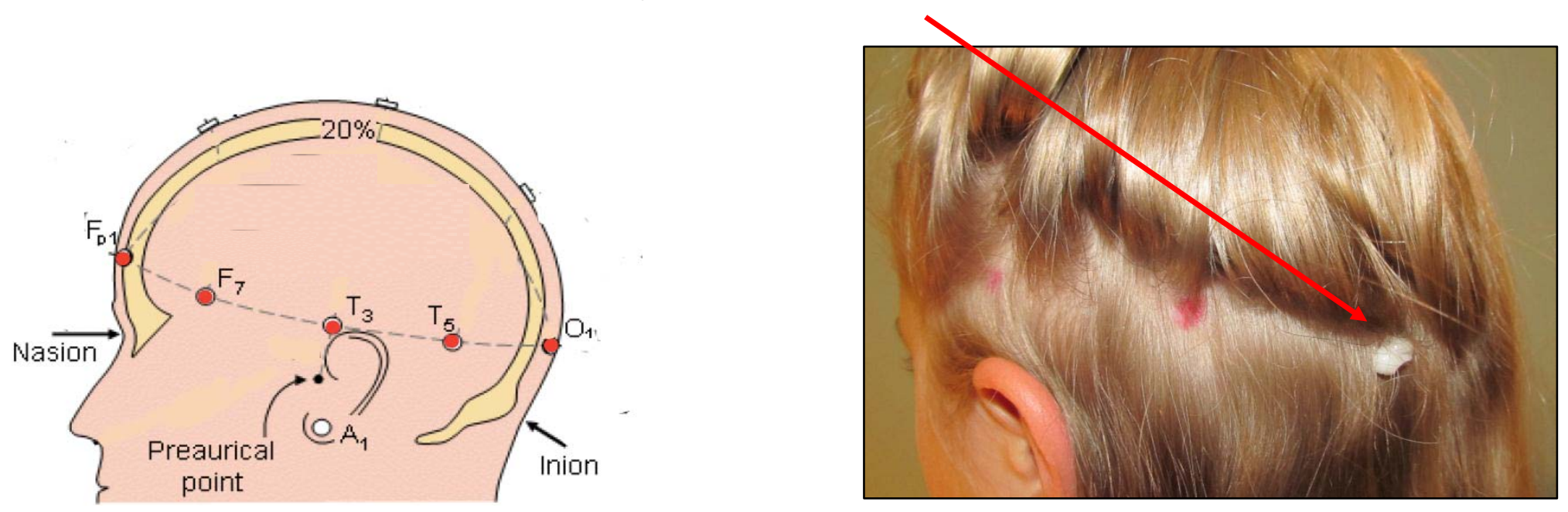

(Repeat the process using T4 to mark O2) 


\section{OB ERS}

\section{0-20 EEG Placement}

\section{Measurement - F3}

- Measure Fp1 to C3 and mark midpoint

- Measure Fz to F7 and mark midpoint

- Mark 50\% = F3

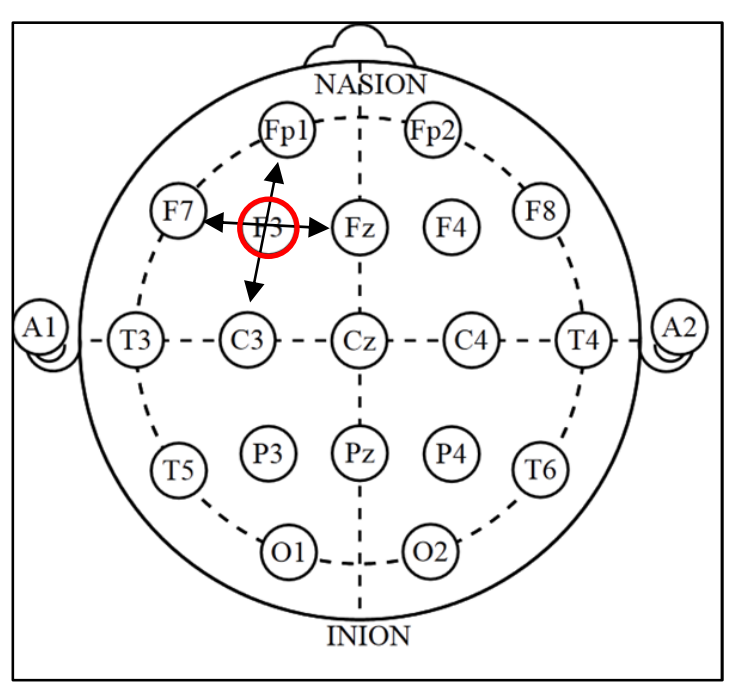

(Repeat the process using Fp2 to C4 \& Fz to F8 to mark F4)

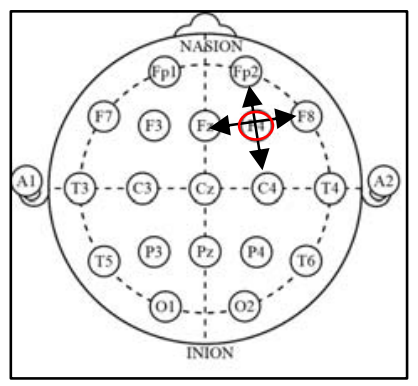




\section{OB ERS}

\section{0-20 EEG Placement}

Measurements M1 \& M2

- M1 \& M2 are the reference electrodes (formally known as A1 \& A2)

- M1 \& M2 are placed on the mastoid (M) process.

- These are the bony prominences behind the ears.

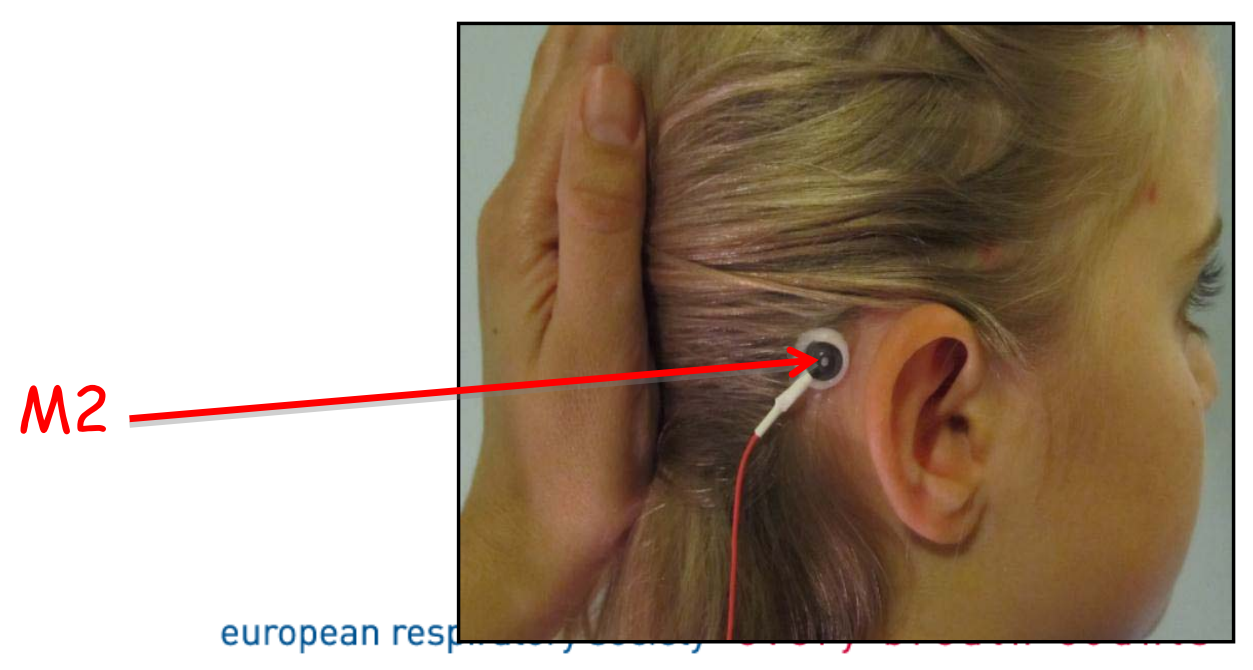


O ERS

\section{0-20 EEG Placement}

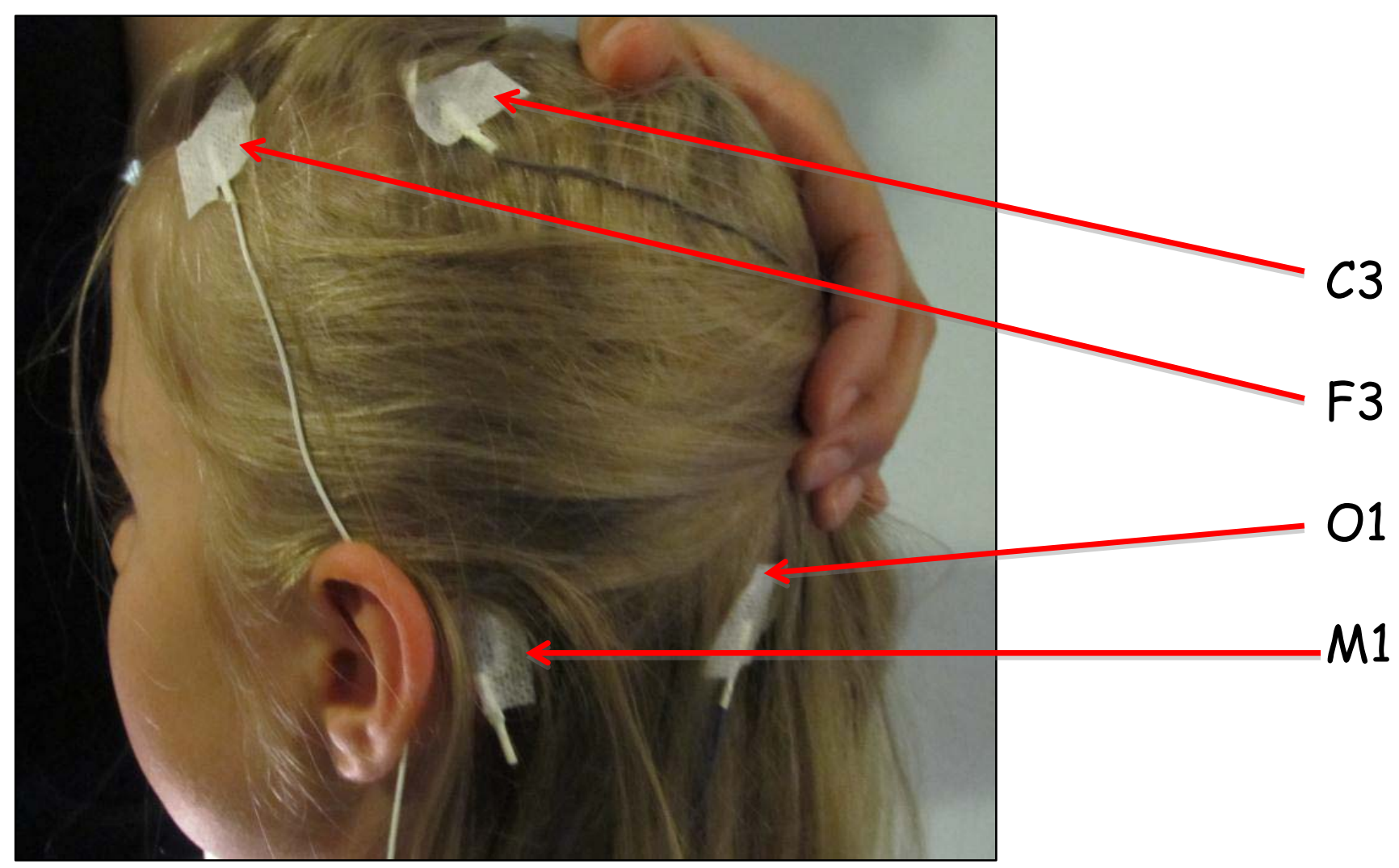

You have now completed a 10-20 EEG montage !! 


\section{OB ERS}

\section{0-20 EEG Placement}

\section{Electro-oculogram}

- Recording of the movement of the corneo-retinal potential difference, not the movement of eye muscle.

- Electrodes are placed at outer canthus of eyes offset $1 \mathrm{~cm}$ above/below the horizontal

- Right out and up / Left out and down
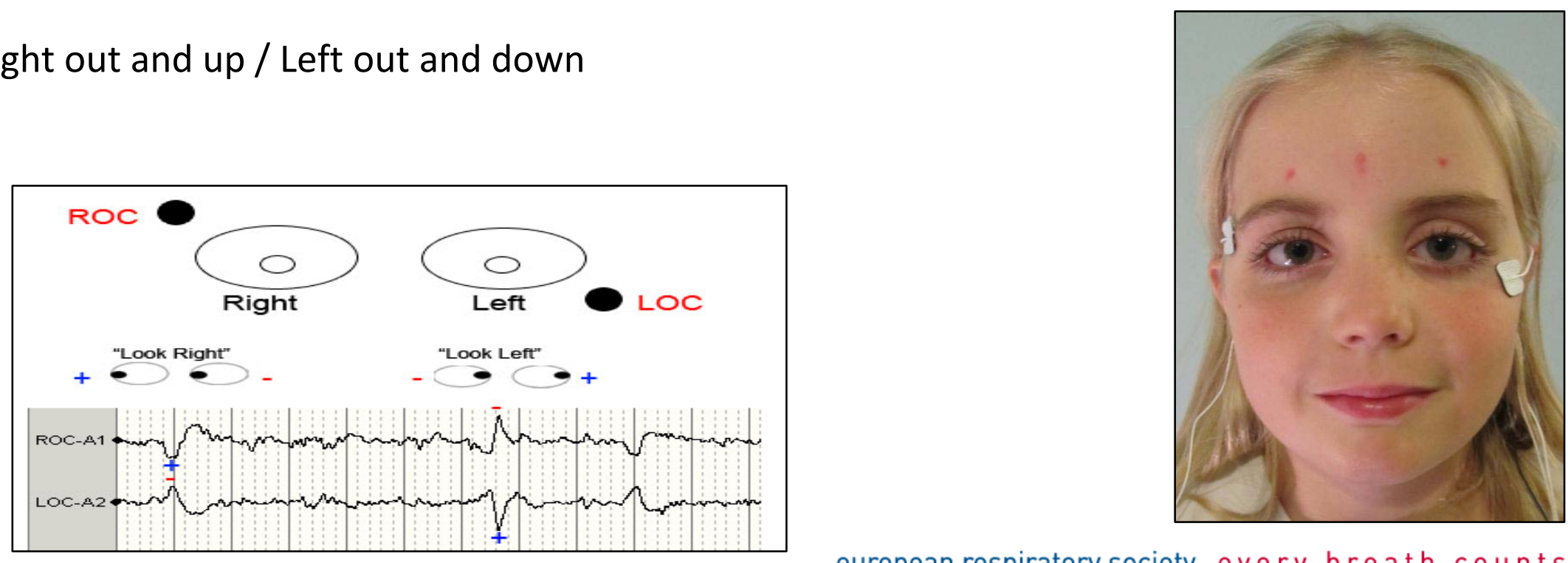


\section{OB ERS}

\section{0-20 EEG Placement}

\section{Electromyogram (Chin EMG)}

- 3 electrodes

- 1 on mentalis

- 2 on submentalis $-2 \mathrm{~cm}$ apart (1cm in Paediatrics)

1 Mentalis

2 Submentalis

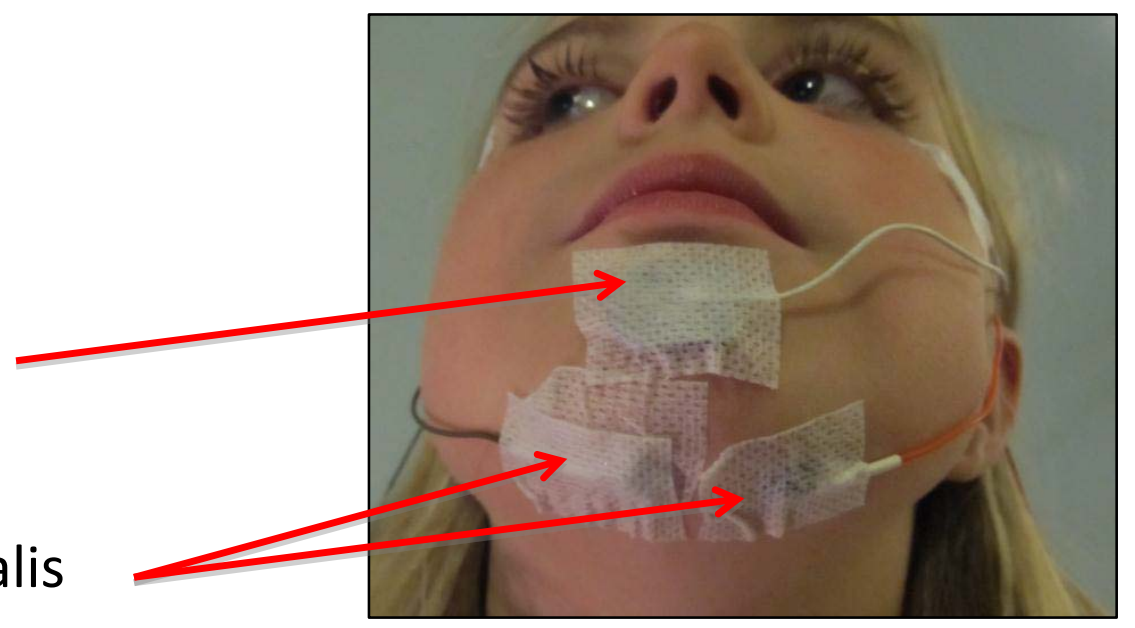




\section{(1) ERS}

\section{0-20 EEG Placement}

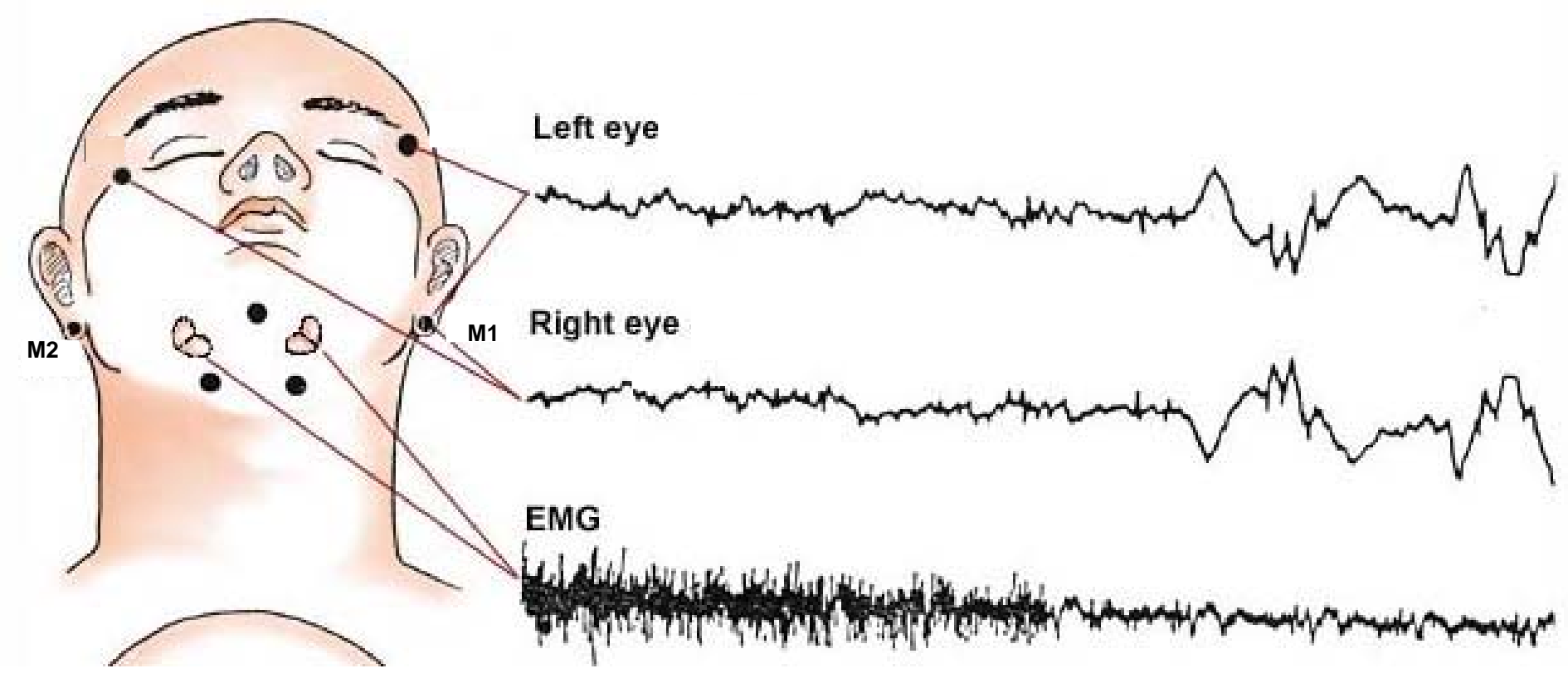

You have now completed the EOG \& EMG elements of a sleep montage setup !! 


\section{ERS}

\section{0-20 EEG Placement}

\section{Calibration (Checking the signals)}

- Eyes closed for 30 seconds

Ask the patient to close his/her eyes \& lie quietly.

- Eyes open for 30 seconds

Ask the patient to open his/her eyes \& look straight ahead.

- Look right \& left

Ask the patient without their head to look to the right then to the left several times.

- Look up \& down

Ask the patient without moving their head to look up then down several times.

- Blink eyes

Ask the patient to blink their eyes 5 times.

- Clench jaw

Ask the patient clench their jaw.

- Flex foot

Ask the patient to point \& flex their foot. Repeat for other foot. Repeat for each leg and document

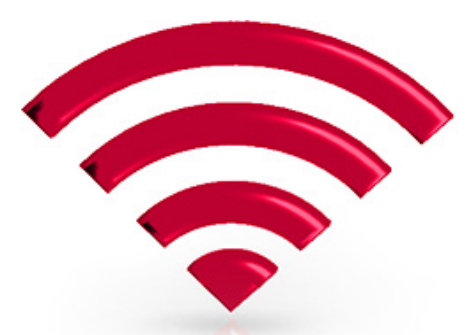

- Breathe in \& out

Ask the patient to breathe normally, and then take a breath in and out. Check polarity and mark IN \& OUT on study.

- Snore sound

Ask the patient to imitate a snore sound. 
(i) ERS

\section{0-20 EEG Placement}

\section{Practical Session}

\section{Your turn !!!}

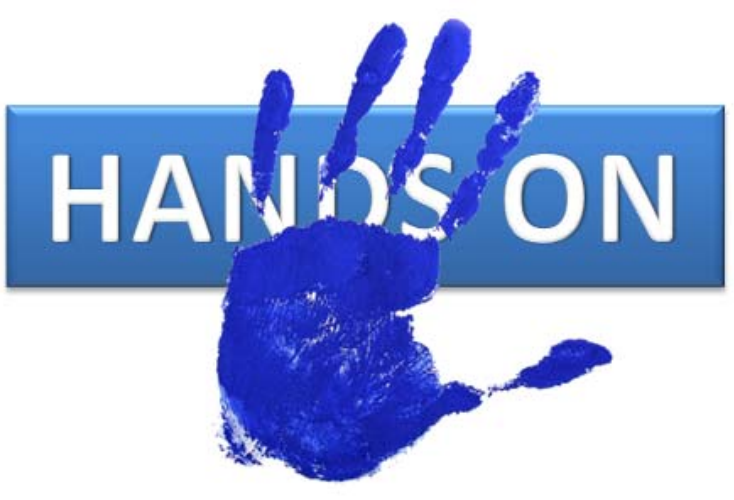




\section{(1) ERS}

\section{Further Reading}

The AASM annual for the Scoring of Sleep and Associated Events: Rules, Terminology and technical Specifications. Version 2.1 American Academy of Sleep Medicine (2014)

Sleep Medicine Textbook (European Sleep Research Society (ESRS)

Claudio Bassetti, Zoran Dogas, Philippe Peigneux, Regensburg, (2014)

Essentials of Polysomnography.

William H. Spriggs; Jones \& Bartlett Publishers (2008)

Essentials of Sleep Technology

Richard S. Rosenberg; American Academy of Sleep Medicine (2010)

Atlas of Clinical Polysomnography Second Edition (Two-volume Set)

Nic Butkov Media matrix , (2011)

The ten twenty system of the International Federation. Electroencephalography and Clinical

Jasper, H.H. , Neurophysiology, 1958, 10:371-375.

Polysomnographic technique: An overview. In: Sleep disorders medicine, 2nd ed. Boston

Chokroverty S. Butterworth Heinemann (1999)

Fundamentals of EEG technology, Volume 1: Basic concepts and methods.

Tyner F, Knott J, Mayer W Jr. New York: Raven Press; (1983).

Sleep medicine.

Lee-Chiong T, Sateia M, Carskadon M, (Hanley \& Belfus, 2002) 


\section{Further Training}

- Practical Polysomnography - Edinburgh, UK

- Various dates

- Edinburgh Sleep Medicine Course - Edinburgh, UK

- March 2016

- European Sleep School - Orihuela Costa, Spain

- Various dates

- International Sleep Medicine Course - Cardiff, UK

- June 2016 


\title{
(1) ERS
}

\section{Any Questions?}

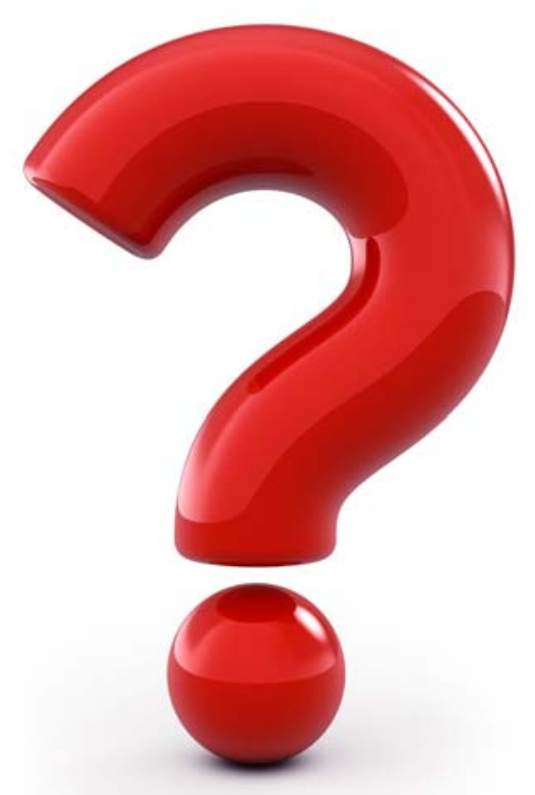

\section{Andrew.morley@ggc.scot.nhs.uk}

\author{
Lizzie.hill@nhs.net
}

